\title{
Carrageenan Biopolymer for Medical Ultrasonography using Phantom CIRS
}

\author{
Anak Agung Aris Diartama ${ }^{1 *}$, Suryono Suryono ${ }^{2}$, Sugiyanto Sugiyanto ${ }^{3}$, Putu Irma \\ Wulandari $^{1}$, I Putu Eka Juliantara ${ }^{1}$, Kadek Yuda Astina ${ }^{1}$ \\ ${ }^{1}$ Radiodiagnostic Engineering and Radiotherapy Academy/ATRO of Bali \\ ${ }^{2}$ Department of Physics, Faculty of Science and Mathematics, Diponegoro University, Semarang, \\ Indonesia \\ ${ }^{3}$ Health Polytechnic of the Ministry of Health of Semarang, Indonesia
}

\begin{abstract}
The use of polymer as conductor in medical ultrasonography is very crucial to establish patient diagnosis and to prevent administration of improper treatment. Rapid development in science and technology encourages people to create more innovations that are readily usable. However, these innovations sometimes put health and environmental aspects aside that in turn become disadvantageous to health and may lead to environmental pollution. This research proposes the use of carrageenan biopolymer as a safe alternative for people's health and the environment. It aims to prove differences in resulting phantom CIRS images taken with the help of carrageenan gel and standard gel based on Carbomer 940 as acoustic coupling agents (ACA) for ultrasonography (USG). It is an experimental research that uses true experiment technique with posttest only control group design. Results from T-test analysis show significance value of $\mathrm{p}>0.05$, meaning there is no significant difference between the use of carrageenan gel and ACA gel (Carbomer 940). This result proves that carrageenan gel can be used as an acoustic coupling agent for ultrasonography. Results from imaging tests also reveal that there is no difference between the use of carrageenan gel and that of a manufacturer gel based on Carbomer 940 available in Indonesia, in terms of visualization of phantom CIRS images.
\end{abstract}

Keywords. Carrageenan; Acoustic Coupling Agent; Ultrasonography.

* Corresponding author: diartamaaris@gmail.com 


\section{Introduction}

The use of medical applications is essential in supporting diagnosis and patient care. Medical applications also require conductors to improve their efficiency and to come up with proper diagnosis. Synthetic polymers now available in the market has been consumed more than one million ton annually across the world. Carbomer 940 belongs to the category chemical based synthetic polymer (non-biodegradable) used as gel basis in acoustic coupling agent for USG [1]. Components containing synthetic formula have greater potential to pollute the environment and they cannot be degraded by microorganism. This means that they do not rot, and any soil polluted with these becomes infertile and cannot be used for planting. The other effect of synthetic polymer use is thinner ozone layer that in turn results in sunburn and skin inflammation (psoriasis). Either way, there are certain criteria of best practices in using polymer preparation as acoustic connectors, namely gels that are soluble in water [2].

Carrageenan is a unique material in that it is hydrophilic, environmentally friendly, three-dimensionally viscoelastic that allows for diffusion, and has molecular and cellular cross link. Wide spectrum carrageenan can be used to produce polymer of specific and typical characteristics. Carrageenan cultivation can be made into useful products of high market value. Carrageenan has been widely used in both food and non-food industries as viscosity control and gel formation, toothpaste stabilizer, wrapper for drugs, and raw material for hydrogel [3-5].

The use of carrageenan as USG acoustic coupling agentmust first undergo testing and image analysis using CIRS. Phantom CIRS is the phantom QA (quality assurance) for ultrasonography. After QA, it can then be used as multi-frequency transducer using different frequencies every six months. The QA test includes image visual homogeneity, and quantitative evaluation for vertical distance accuracy, horizontal distance accuracy, and maximum penetration accuracy[6].

Gel in transducer is used as ultrasonic wave conductor in USG examination. Without this ACA gel, the air will make a barrier that reflect ultrasonic wave, hence transmission is blocked. In the context of ultrasonic wave in health, the transducer used refers to ultrasonic transducer that turn acoustic signal into electrical signal, and vice versa. A transducer consists of one or more piezoelectric elements [7].

When an electric pulse run through a piezoelectric element, the latter vibrates and generates ultrasonic wave. Likewise, when a piezoelectric element vibrates, an echo pulse is reflected. When an ultrasonic transducer transmits acoustic pulse of short duration to a reflective surface, the reflected pulse is affected by object properties. This results in increased echo signal coming into receiving transducer. Generator pulse functions to produce electric pulse to be used by the transducer. Conventional ultrasonic imaging generates an average of 1000 pulses per second. Basic controlling principle of generator pulse is based on the amount of electric pulse used to change the intensity of ultrasonic scattering [8].

Ultrasonic images depict varied acoustic impedance from different tissues. This is due to varied density and capability of different tissues, such as those of bone and liver. In its simple form, pressure from ultrasonic wave is transmitted by the transducer along a single imaging line, and as this pressure propagates, echo is reflected off objects along that line. Images are displayed as maps of echo in the form of image brightness and mapping of incidence. This process is repeated until a two-dimensional image is obtained. Image analysis is carried out to identify structural components. In the meantime, quality of resulting USG image depends on design characteristics of ultrasonic instruments used, the number of instrument variables used, and the operator's skill in finding proper positions. 


\section{Methods}

This is an experimental research using true experiment with posttest only control group design. The statistical analysis used here is the T-test. This research for ultrasonography gel was conducted at the Electromedical Laboratory of Poltekkes Kemenkes Jakarta II by testing quality of USG images using phantom CIRS 054GS which covers vertical distance, horizontal distance, depth of penetration, and anechoic tests.

Testing was performed by preparing each gel sample (carrageenan and Carbomer 940), a separator or thin acrylic the size of the USG probe to measure gel use. The separator was then put on the surface of phantom CIRS and $20 \mathrm{ml}$ of the sample gel was used with the help of a spuit for proper distribution on the separator pattern made, as depicted in the following figure.

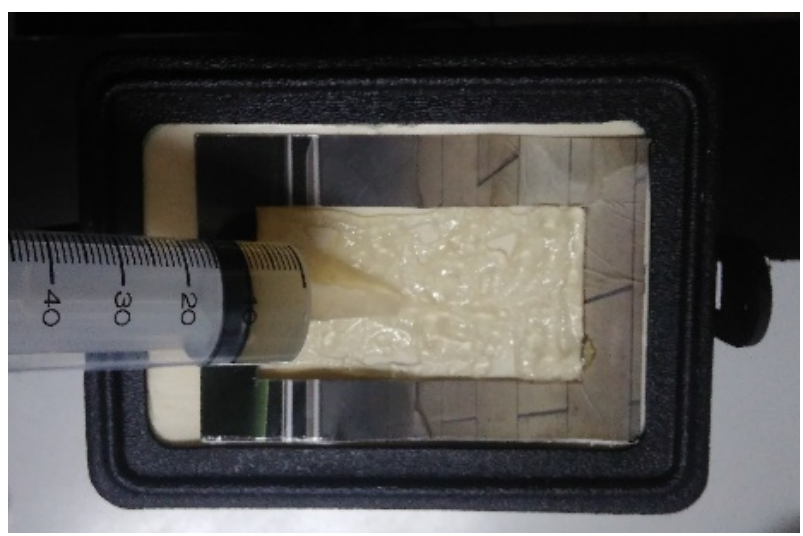

Figure 1. Testing for carrageenan gel limit setting

The USG probe is as normally used in liver examination. Data generated are to be used as reference for further measurements. The transducer is positioned perpendicular to the scanning surface and it is pointed to the object area, as depicted in the following figure.

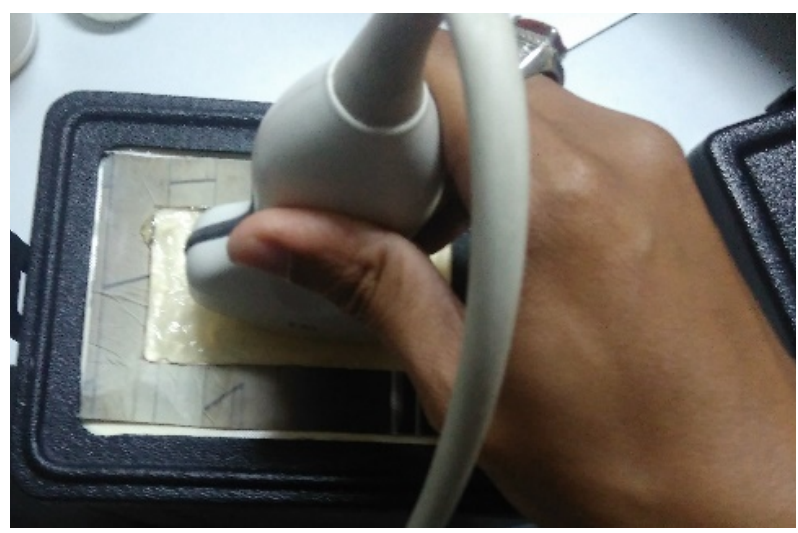

Figure 2. USG transducer position in phantom surface

The transducer is set straight to obtain maximum image. The image obtained is then capturedand saved. The separator is marked with a marker when positioning the transducer on the phantom surface. The resulting image is then observed to see if all areas of similar depth are displayed in similar color intensity throughout the image, to make measurements and to keep the record. Afterwards, the gel is wiped with tissue to dry up the phantom 
surface. Those procedures are repeated for each gel sample with the same transducer positioning and gel amount $(20 \mathrm{ml})$. Measurements made are for vertical distance, horizontal distance, depth of penetration, and anechoic.

Vertical distance makes different measurements, such as penetration depth, beam profile, lateral response width, vertical distance calibration, and focal one of an imaging systems. The line should be perpendicular to the scanning area and the target. Horizontal distance aims to observe points arranged horizontally on the phantom surface. Vertical and horizontal measurements are made by scanning the phantom surface and freezing (choosing) the image, making measurements, and recording visualizations of vertical and horizontal points of the phantom.

Depth of penetration test aims to evaluate the transducer's ability to generate images of the deepest penetration at maximum intensity. USG probe sensitivity determines the weakest echo that can still be well detected and properly displayed. This means that we can practically state the ability of a USG probe in visualizing maximum depth of a resulting USG image. Maximum visualization depth is limited by transducer's frequency, gain, TGC (Time Gain Compensation), focus depth, display format (number of scan lines), output power, and noise of the electronic system. Depth of penetration analysis is performed by scanning the phantom and freezing (choosing) the image, making measurement, and recording visualization of maximum depth of default echo, distance from scanning window to the deepest cylinder or the round object that is barely visible $[9,10]$.

Anechoic analysis test is used to test system's ability to detect and display negative contrast of objects of all sizes. This testing combines aspects of spatial resolution and image homogeneity in one single test. Quality of anechoic object image can also be affected by nose from the probe, lobes side of illumination field of the transducer, and issues in image processing in the hardware. Anechoic analysis is performed by scanning the phantom and freezing (choosing) the image, making measurement, and recording anechoic visualization composed by measuring diameter of each anechoic circle vertically and horizontally of the phantom. In order to find out the percentage of axial and lateral accuracy of measurement results, comparisons can be made between distance from those results and actual distances as stated in the phantom CIRS 054GS book manual [11].

\section{Result Analyses}

The research was conducted from November - December 2016 by making an alternative USG gel based on carrageenan to be tested using phantom CIRS with standard ACA gel (Carbomer 940) as comparison and control. Results of USG images on phantom CIRS from testing for vertical and horizontal distance using carrageenan gel and ACA gel (Carbomer 940) are depicted in the following figure.
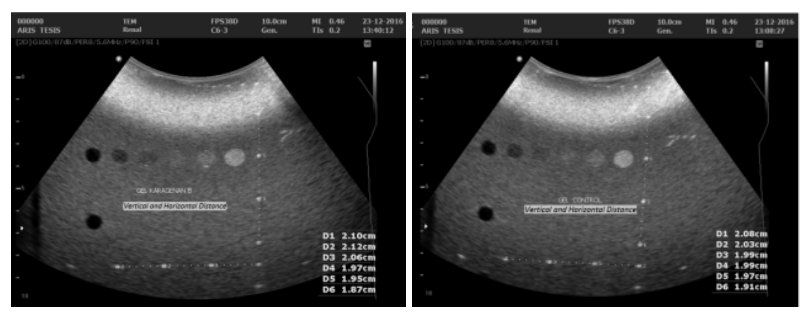

Figure 3. Result of vertical and horizontal distance analysis of carrageenan gel and ACA gel (Carbomer 940) as control. 
The vertical distance has 8 points as targets with the diameter of each point at 100 microns, located at 2 to $16 \mathrm{~cm}$ deep from the phantom surface. Distance from each target point to the real distance of $20 \mathrm{~mm}$ was measured. Results of image testing and T-test significance value analysis for vertical distance on carrageenan gel and USG acoustic coupling agent based on Carbomer 940 are given in the following table.

Table 1. Results of image testing and T-test value comparison analysis for vertical distance

\begin{tabular}{lcccc}
\hline Gel Type & $\begin{array}{c}\text { Mean } \\
(\mathrm{cm})\end{array}$ & $\begin{array}{c}\text { Actual } \\
\text { size } \\
(\mathrm{cm})\end{array}$ & $\begin{array}{c}\text { Accuration } \\
\text { Level }\end{array}$ & $\begin{array}{c}\text { Sig. } \\
(2- \\
\text { Tailed })\end{array}$ \\
\cline { 1 - 4 } $\begin{array}{l}\text { Carrageenan } \\
\text { Gel }\end{array}$ & 1.93 & 2 & 96.50 & \\
\cline { 1 - 4 } $\begin{array}{l}\text { Karbomer } \\
940 \text { (control) }\end{array}$ & 1.96 & 2 & 97.83 & \\
\hline
\end{tabular}

The table shows that for vertical distance test, standard manufacturer gel (Carbomer 940 is closer to actual distance (1.96 cm with an accuracy of $97.83 \%$ ), compared to carrageenan gel (1.93 cm with an accuracy of $96.50 \%)$.

Concerning vertical distance, results from data normality analysis shows that data for carrageenan gel and control gel (Carbomer 940) are normally distributed ( $p>0.05)$. T-Test for carrageenan gel and control gel (Carbomer 940) reveals significance value of 0.530 or $p$ $>0.05$, which means that there is no significant difference.

The horizontal distancehas 7 points as targets with the diameter of each point at 100 microns, located at 2 to $16 \mathrm{~cm}$ deep from the phantom surface. Each point in the horizontal group is separated $20 \mathrm{~mm}$ apart. Results of image testing and T-test significance value analysis for horizontal distance on carrageenan gel and USG acoustic coupling agent based on Carbomer 940 are given in the following table.

Table 2. Results of image testing and T-test value comparison analysis for horizontal distance

\begin{tabular}{lcccc}
\hline Gel Type & $\begin{array}{c}\text { Mean } \\
(\mathrm{cm})\end{array}$ & $\begin{array}{c}\text { Actual } \\
\text { size } \\
(\mathrm{cm})\end{array}$ & $\begin{array}{c}\text { Accuration } \\
\text { Level }\end{array}$ & $\begin{array}{c}\text { Sig. } \\
(2- \\
\text { Tailed })\end{array}$ \\
\cline { 1 - 4 } $\begin{array}{l}\text { Carrageenan } \\
\text { Gel }\end{array}$ & 2.09 & 2 & 95.54 & \\
\cline { 1 - 4 } $\begin{array}{l}\text { Karbomer } \\
940 \text { (control) }\end{array}$ & 2.03 & 2 & 98.36 & \\
\hline
\end{tabular}

The table shows that for horizontal distance test, standard manufacturer gel (Carbomer 940 is closer to actual distance $(2.03 \mathrm{~cm}$ with an accuracy of $98.36 \%)$, compared to carrageenan gel $(2.09 \mathrm{~cm}$ with an accuracy of $95.54 \%)$. Concerning horizontal distance, results from data normality analysis shows that data for carrageenan gel and control gel (Carbomer 940) are normally distributed $(\mathrm{p}>0.05)$. T-Test for carrageenan gel and control gel (Carbomer 940) reveals significance value of 0.129 or $p>0.05$, which means that there is no significant difference.

Results of USG image's depth of penetration on phantom CIRS are depicted in the following figure. 


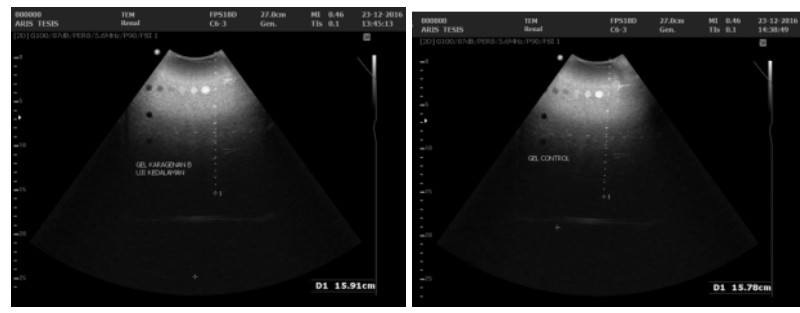

Figure 4. Results of USG image of carrageenan gel and ACA gel (Carbomer 940)

Depth of penetration is the greatest distance of a phantom with a maximum depth of 16 $\mathrm{cm}$. Distance measurement is made from the phantom surface to the last target point (vertical distance point) observable in an USG image. Results of image testing for depth penetration on carrageenan gel and USG acoustic coupling agent based on Carbomer 940 are given in the following table.

Table 3. Results of USG image test for penetration depth on research sample

\begin{tabular}{ccccc}
\hline Gel Type & $\begin{array}{c}\text { Mean } \\
(\mathrm{cm})\end{array}$ & $\begin{array}{c}\text { Actual } \\
\text { size } \\
(\mathrm{cm})\end{array}$ & $\begin{array}{c}\text { Accuration } \\
\text { Level }\end{array}$ & $\begin{array}{c}\text { Sig. } \\
(2- \\
\text { Tailed })\end{array}$ \\
\cline { 1 - 3 } $\begin{array}{c}\text { Carrageenan } \\
\text { Gel }\end{array}$ & 15.12 & 16 & 94.50 & \\
\cline { 1 - 3 } $\begin{array}{c}\text { Karbomer } \\
940 \text { (control) }\end{array}$ & 14.85 & 16 & 92.81 & \\
\hline
\end{tabular}

The table shows that for depth of penetration test, carrageenan gel is closer to actual distance (15.12 cm with an accuracy of $94.50 \%$ ), compared to ACA gel (Carbomer 940) $(14.85 \mathrm{~cm}$ with an accuracy of $92.81 \%$ ). Concerning depth of penetration, results from data normality analysis shows that data for carrageenan gel and control gel (Carbomer 940) are normally distributed $(\mathrm{p}>0.05)$. T-Test for carrageenan gel and control gel (Carbomer 940) reveals significance value of 0.877 or $\mathrm{p}>0.05$, which means that there is no significant difference.

Results of USG image test for anechoic on phantom CIRS with carrageenan gel and ACA gel (Carbomer 940) are depicted in the following figure.
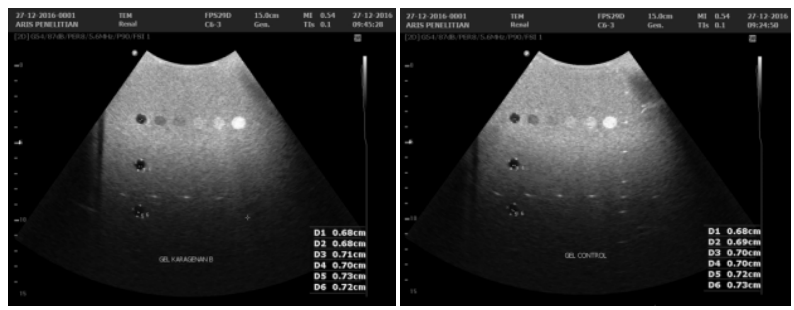

Figure 5. Results of USG image for anechoic on carrageenan gel and ACA gel (Carbomer 940)

Anechoic cylinderis made of zerdine consisting of 5 cylinders with anechoic contrast each with $8 \mathrm{~mm}$ diameter located at 4, 7, 10, 13 and $16 \mathrm{~cm}$ depth. Evaluation is made by measuring anechoic diameter in USG monitor. Results of image testing and T-test significance value analysis for anechoic on carrageenan gel and USG acoustic coupling agent based on Carbomer 940 are given in the following table. 
Table 4. Results of USG image for anechoic on carrageenan gel and ACA gel (Carbomer 940)

\begin{tabular}{ccccc}
\hline Gel Type & $\begin{array}{c}\text { Mean } \\
(\mathrm{cm})\end{array}$ & $\begin{array}{c}\text { Actual } \\
\text { size } \\
(\mathrm{cm})\end{array}$ & $\begin{array}{c}\text { Accuration } \\
\text { Level }\end{array}$ & $\begin{array}{c}\text { Sig. (2- } \\
\text { Tailed) }\end{array}$ \\
\cline { 1 - 4 } $\begin{array}{c}\text { Carrageenan } \\
\text { Gel }\end{array}$ & 0.70 & 0.8 & 87.91 & 0.1000 \\
\cline { 1 - 4 } $\begin{array}{c}\text { Karbomer } \\
940 \text { (control) }\end{array}$ & 0.70 & 0.8 & 87.91 & \\
\hline
\end{tabular}

The table shows that for anechoic test, both carrageenan gel and ACA gel has similar accuracy of $87.91 \%$ at a distance of $0.70 \mathrm{~mm}$. Concerning anechoic, results from data normality analysis shows that data for carrageenan gel and control gel (Carbomer 940) are normally distributed $(\mathrm{p}>0.05)$. T-Test for carrageenan gel and control gel (Carbomer 940) reveals significance value of 0.1000 or $\mathrm{p}>0.05$, which means that there is no significant difference.

Imaging test using phantom CIRS was performed to figure out the ability of gels in transmitting ultrasonic wave and to test USG evaluate results. Tests at each point for vertical and horizontal distance, depth of penetration, and anechoic show average values not far offbetween carrageenan gel and ACA gel (Carbomer 940). In their roles as acoustic coupling agents forUSG, both carrageenan gel and ACA gel (Carbomer 940) are able to transmit ultrasonic wave properly and hence, creating quality images. This is because in principle, ultrasonic wave can propagate or be transmitted in solid, liquid, and gaseous media [12]. With the help of carrageenan gel, the air trapped between the transducer and the phantom surface can be eliminated. Hence, carrageenan is capable of performing as an ACA in ultrasonography. ACA gel penetrates the air between the transducer and the surface of an object [2].

Results of analysis using T-test for phantom CIRS imaging comprising vertical and horizontal distance, depth of penetration, and anechoic tests showsignificance values of $p>$ 0.05 , which means no significant difference between the use of carrageenan gel and ACA gel (Carbomer 940), as both agents can help properly visualize images in phantom CIRS. Carrageenan is a natural polymer, whereas Carbomer 940 is its synthetic counterpart. Both carrageenan and Carbomer 940 can be used to make gels. Carrageenan comes with tertiary helical structure that enables it to form gel $[13,14]$.

Carrageenan gel as an acoustic coupling agent is capable of producing images on the phantom CIRS by getting rid of artifacts caused by the presence of air. This proves that carrageenan gel reduces the air trapped between the transducer and the phantom CIRS surface to allow for perfect ultrasonic wave transmission. Without ACA gel or lack of any coupling medium, the air reflects $100 \%$ ultrasonic wave that it cannot be transmitted [15].

\section{Conclusion}

Results from this research show that carrageenan gel can be used as an acoustic coupling agent in ultrasonography. Results from imaging tests also prove that there is no significant difference between carrageenan and one of manufacturer gel based on Carbomer 940 readily available in Indonesia, in terms of image visualization on phantom CIRS. 


\section{References}

1. Anggraeni Y, Hendradi E, Purwanti T. Karakteristik sediaan dan pelepasan natrium diklofenak dalam sistem niosom dengan basis gel carbomer 940. Pharma Scientia. 1(1):1-15 (2012)

2. Palmer K, Oates WE, Portney PR. Tightening environmental standards: the benefit-cost or the no-cost paradigm? Journal of economic perspectives. 9(4):119-32 (1995)

3. Madan B, Mandal B, Kumar S, Ghosh B. Canscora decussata (Roxb.) Schult (Gentianaceae) inhibits LPS-induced expression of ICAM-1 and E-selectin on endothelial cells and carageenan-induced paw-edema in rats. Journal of ethnopharmacology. 89(2-3):211-6 (2003)

4. Meena R, Prasad K, Siddhanta A. Development of a stable hydrogel network based on agar-kappa-carrageenan blend cross-linked with genipin. Food Hydrocolloids. 23(2):497-509 (2009)

5. Cascone S, Lamberti G. Hydrogel-based commercial products for biomedical applications: A review. International journal of pharmaceutics. 2020;573:118803 (2020)

6. Tradup D, Hangiandreou N, Taubel J. Comparison of ultrasound quality assurance phantom measurements from matched and mixed scanner-transducer combinations. Journal of applied clinical medical physics. 4(3):239-47 (2003)

7. Phani D, Thomas A, Paramu R, Singh MS, Muraleedharan V, Nair R. Acoustic and Ultrasonographic Characterization of Neoprene, Beeswax, and Carbomer-Gel to Mimic Soft-tissue for Ultrasound. arXiv preprint arXiv:200405355. 2020.

8. Drakos T, Giannakou M, Menikou G, Ioannides C, Damianou C. An improved method to estimate ultrasonic absorption in agar-based gel phantom using thermocouples and MR thermometry. Ultrasonics. 103:106089 (2020)

9. Nguyen TP, Nguyen VT, Mondal S, Pham VH, Vu DD, Kim B-G, et al. Improved Depth-of-Field Photoacoustic Microscopy with a Multifocal Point Transducer for Biomedical Imaging. Sensors. 20(7) (2020)

10. Abbas S, Peng P. Basic Principles and Physics of Ultrasound. Ultrasound for Interventional Pain Management: Springer; p. 1-31 (2020)

11. Rafailidis V, Huang DY, Yusuf GT, Sidhu PS. General principles and overview of vascular contrast-enhanced ultrasonography. Ultrasonography. 39(1):22 (2020)

12. Wang X, Majzoobi M, Fanahnaky A. Ultrasound-assisted modification of functional properties and biological activity of biopolymers: A review. Ultrasonics Sonochemistry. 105057 (2020)

13. Glicksman M, editor Utilization of seaweed hydrocolloids in the food industry. Twelfth international seaweed symposium; Springer (1987)

14. Ibañez MaC, Ferrero C. Extraction and characterization of the hydrocolloid from Prosopis flexuosa DC seeds. Food Research International. 36(5):455-60 (2003)

15. Troia A, Cuccaro R, Schiavi A. Independent tuning of acoustic and mechanical properties of phantoms for biomedical applications of ultrasound. Biomedical Physics \& Engineering Express. 3(2):025011 (2017) 